\title{
Depression among pregnant women: A hospital based study
}

\section{Shrestha $D^{1}$}

'Dipty Shrestha, Lecturer, Department of Obstetrics and Gynaecology, Kathmandu Medical College Teaching Hospital, Kathmandu, Nepal

\begin{abstract}
Background: Being a mother for every woman is of great pride. But this moment of happiness and pride is associated with depression that might affect the health of both the mother and the baby. So this matter has to be looked into and taken care of but is not being done especially in our context.

Objective: To identify the prevalence of depression and its severity in pregnant women from 14 weeks to 36 weeks of gestation at Kathmandu Medical College and Teaching Hospital.

Methods: This is a descriptive and prospective study where 195 pregnant women from 14 weeks to 36 weeks of gestation were enrolled.The study was conducted at Kathmandu Medical College and Teaching Hospital from $1^{\text {st }}$ October 2015 to $1^{\text {st }}$ February 2016. The Centre For Epidemiologic Studies Depression Scale was used in this study to identify depression in pregnancy. This is a structured scale used worldwide to study the relationship between depression and pregnancy. It consists of 20 items; each given a score of $0,1,2$ and 3. A total score of 16 or more is considered depression. After taking informed consent, cases fulfilling the inclusion criteria were asked questions as per the scale and scoring were done.

Results: Among the total 195 cases, eight (4.1\%) had CESD scale scoring above 16 indicating depression and among these eight cases, five were in the age group of $18-25$ years, two in the age group of $26-30$ years and one in the age group of more than 30 years.

Conclusion: This study did not show definite relationship between depression and pregnancy.
\end{abstract}

Key words: Depression, Pregnancy

\section{INTRODUCTION}

T $\mathrm{n}$ today's world, pregnancy is gaining more importance and attention. Nowadays, wide range of care is being given to the pregnant women to uplift their health. One addition is care of mood changes in pregnancy. Antenatal depression, particularly mild depressive symptoms may be overlooked by health care providers during antenatal assessment as it is likely attributed to emotional changes of pregnancy hormones ${ }^{1}$.

Antenatal depression is a public health concern due to its negative effect on the general health of the woman and its association with underutilization of antenatal care services, complications during pregnancy, negative

\section{Address for correspondence}

Dr. Dipty Shrestha

Lecturer, Department of Obstetrics and Gynaecology

Kathmandu Medical College Teaching Hospital

Sinamangal, Kathmandu, Nepal

E-mail: diptyshrestha@hotmail.com experience of childbirth, adverse pregnancy outcomes (e.g., preterm birth, low birth weight, still birth, and birth asphyxia), and infant mortality and morbidity (i.e., poor infant growth and development) 2,3. Moreover, the magnitude of the impact of antenatal depression varies across socioeconomic status ${ }^{4,5}$. The World Health Organization (WHO) estimates that by the year 2020, depressive disorders will be the leading cause of global disease burden in women ${ }^{6}$.

Depression in pregnancy might be under looked assuming it to be the part of normal pregnancy which might have a negative impact on the health of the mother and the foetus.There are many scales to measure the mood changes and depression during pregnancy and among these CESD (Centre for Epidemiologic Studies Depression) scale is used most commonly worldwide. CESD scale is a short and structured scale that was originally developed by Lenore Radloff.This scale consists of 20 items; each item given a score of 0, 1, 2 and 3and the score of 16 or more is considered depression. Past work supports using a CESD cut-off score of 16 or higher 
to indicate subjects with major depression(sensitivity $=0.99$, specificity $=0.56)^{7}$. Depression is the leading cause of disease-related disability among women ${ }^{8}$, and women are also 1.6-1.7 times more likely to suffer from depression and/or AD during their lifetime than men?

In our context, women are under unnecessary burden and stress which is further aggravated during pregnancy. So, this study was conducted at Kathmandu Medical College and Teaching Hospital (KMCTH) with the objectives to identify the prevalence of depression and its severity in pregnant women from $14-36$ weeks of gestation.

\section{METHODS}

This is a descriptive and prospective study conducted at KMCTH from $1^{\text {st }}$ October 2015 to $1^{\text {st }}$ February 2016. A total of 195 pregnant women coming for antenatal care were taken into account. The inclusion criteria included pregnant women from 14 weeks to 36 weeks of gestation. The exclusion criteria included pregnant women with history of depression or any mental illness, pregnant women with family history of mental illness and pregnant women with history of drug abuse.

All the cases enrolled in the study by purposive sampling, were explained about the study and informed consent was taken. The cases were interviewed in Outpatient Department (OPD). Questionnaire was developed along with the CESD mood scale.The questionnaire included demographic profile, general history, past and present obstetrics history, history of past illness, family history as well as other measures assessing the psychosocial stress like alcohol and drug abuse and domestic violence. Each case was asked questions as per the scale used in the study and scoring was done.

The CESD scale has been used in this study as it is short and a structured measure. It includes 20 items to study relationship between depression and pregnancy. Scoring of 0, 1, 2 and 3 are allotted to the symptoms that are present rarely or none of the time, some or little of the time, occasionally or a moderate amount of time, and all of the time, respectively- except for questions $4,8,12$ and 16 where the scoring is reverse. Total score of 16 or higher is considered as having depression.

All the data were entered and analysed with SPSS version 20. Data is presented in frequencies, charts and percentage. Chi square test and Fisher's exact tests were applied, and $\mathrm{p}<0.05$ was considered statistically significant.

\section{RESULTS}

In the study, altogether 195 cases were enrolled. Among these, eight (4.1\%) had CESD scale scoring of more than 16 indicating depression. Among these eight cases, five were in the age group of 18 - 25 years, two in the age group of 26 - 30 years and one in the age group of more than 30 years. Most of the cases in the study were primigravida (51.7\%).

Table 1: Distribution of participants in relation to age $(\mathbf{n}=195)$

\begin{tabular}{cccccccc}
\hline $\begin{array}{c}\text { Depression } \\
\text { (CESD } \geq \mathbf{1 6 )}\end{array}$ & \multicolumn{2}{c}{$\mathbf{1 8 - 2 5}$} & \multicolumn{3}{c}{ Age (years) } \\
& Frequency & Percent & Frequency & Percent & Frequency & Percent \\
Present & 5 & 4.6 & 2 & 3.17 & 1 & 4.3 \\
Absent & 104 & 95.4 & 61 & 96.8 & 22 & 95.6 \\
Total & $\mathbf{1 0 9}$ & $\mathbf{1 0 0}$ & $\mathbf{6 3}$ & $\mathbf{1 0 0}$ & $\mathbf{2 3}$ & $\mathbf{1 0 0}$ \\
\hline
\end{tabular}

Table 2: Distribution of Participants in relation to parity

\begin{tabular}{|c|c|c|c|c|c|}
\hline \multirow{3}{*}{ Parity } & \multicolumn{4}{|c|}{ Depression (CESD $\geq 16$ ) } & \multirow{3}{*}{ Total } \\
\hline & \multicolumn{2}{|c|}{ Present } & \multicolumn{2}{|c|}{ Absent } & \\
\hline & Frequency & Percent & Frequency & Percent & \\
\hline Primigravida & 5 & 4.9 & 96 & 95.04 & 101 \\
\hline Multigravida & 3 & 3.19 & 91 & 96.8 & 94 \\
\hline
\end{tabular}




\section{DISCUSSION}

Nowadays, assessment of depression in pregnancy has become an important component of antenatal care as antenatal depression has shown to be associated with adverse neonatal outcome as well as postpartum depression which in turn might affect the taking care of the neonates. Improving the health status during pregnancy will uplift the maternal and neonatal outcome thus alleviation of psychosocial stress during pregnancy is essential.

Psychosocial stress in pregnancy is defined as "the imbalance that a pregnant woman feels when she cannot cope with demands which is expressed both behaviourally and physiologically"10. It has recently come to the forefront of policy. However, with the American College of Obstetricians and Gynaecologists (ACOG) releasing a 2006 committee opinion states that psychosocial stress may predict a woman's "attentiveness to personal health matters, her use of prenatal services, and the health status of her offspring ${ }^{\prime 10}$. In this committee opinion, ACOG advocated screening all women for psychosocial stress and other psychosocial issues during each trimester of pregnancy and the postpartum period ${ }^{11}$.

In this study, among the total 195 pregnant women,eight of them had scoring of 16 or more signifying depression (4.1\%). In another similar study by Jennifer Wu et al, among 1697 studied population 264 of them had CESD scoring of 16 and more that represented $15.6 \%$ of the

\section{REFERENCES}

1. Brown MA, Solchany JE. Two overlooked mood disorders in women:subsyndromal depression and prenatal depression. NursClin North Am.2004;39(1):83-95.

2. Rondo PH, Vaz AJ, Moraes F, Tomkins A. The relationship between salivary cortisol concentrations and anxiety in adolescent and nonadolescent pregnant women. Braz J Med Biol Res. 2004;37(9):1403-9.

3. Alder J, Breitinger G, Granado C, Fornaro I, Bitzer J, Hösli I, et al.Antenatal psychobiological predictors of psychological response tochildbirth. J Am Psychiatry Nurses Assoc. 2011;17(6):417-25.

4. Faisal-Curry $A$, Araya $R$, Zugaib $M$, Menezes PR. Common mental disorders during pregnancy and adverse obstetric outcomes. J PsychosomObstetGynaecol.2010;31(4):229-35. total studied population 7 . In a systematic review of studies conducted in 8 African countries (Nigeria, South Africa, Uganda, Ethiopia, Morocco, Gambia, Zimbabwe, Malawi), Sawyer reported a weighted mean prevalence of $11.3 \%^{12}$. Furthermore, a study undertaken in a Tanzania peri-urban setting (an area transitioning between urban and rural; Chamazi and Mbagala), reported an antenatal depression rate as high as $39.5 \%{ }^{13}$ that was very high than my study result. Similar to depression, stress has also been studied in various studies. In astudy conducted by Wood et al, six percent had high stress, $78 \%$ had low to moderate stress and $16 \%$ had no stress ${ }^{14}$. Pantha et al in a tertiary maternity hospital in Kathmandu reported a stress prevalence of 35\% in the first trimester and $34.2 \%$ in the third trimester and most of the respondents were among the age group of $20-29$ years with mean age of 25 years $^{15}$.

In this study, the maximum cases (55.8\%) enrolled were in the age group of 18-25 years, and most of them were primigravida (51.7\%). In a study by Sarah M. Wood et al, among the 1522 study participants, mean age was 30.4 (+/-6.3) years ${ }^{14}$. In another study by Mechtilda et al, $46.9 \%$ were in between the age 18 to 25 years similar to this study, but the findings in this study are contradictory to my findings. Most of them were multigravida (51.6\%) ${ }^{16}$.

\section{CONCLUSION}

In this study, prevalence of depression among antenatal group of women was low. However, a large scale study is required to identify depression in pregnancy.

5. Grote NK, Bridge JA, Gavin AR, Melville JL, lyengar $S$, Katon WJ. A meta-analysis of depression during pregnancy and the risk of preterm birth, low birth weight, and intrauterine growth restriction. Arch Gen Psychiatry. 2010;67(10):1012-24.

6. Department of Reproductive Health and Research WHO. Mental health aspects of women's reproductive health: a global review of the literature. Geneva: World Health Organization; 2009.

7. Weissman MM, Sholomskas D, Pottenger M, Prusoff BA, LockeBZ. Assessing depressive symptoms in five psychiatric populations:a validation study. Am J Epidemiol. 1977;106(3):203-14.

8. Kessler RC, Berglund P, Demler O, Jin R, Merikangas $\mathrm{KR}$, Walters EE. Lifetime prevalence and age-ofonset distributions of DSM-IV disorders in the national comorbidity survey replication. Arch Gen Psychiatry. 2005;62(6):593-602. 
9. Schneider ML, Moore CF, Kraemer GW, Roberts $A D$, DeJesus OT. The impact of prenatal stress, foetal alcohol exposure, or both on development: Perspectives from a primate model. Psychoneuroendocrinology. 2002;27(1-2):285-98.

10. Ruiz RJ, Fullerton JT. The measurement of stress in pregnancy. Nurs Health Sci. 1999;1(1):19-25.

11. American College of Obstetricians and Gynecologists. ACOG committee opinion no. 343: psychosocial risk factors; perinatal screening and intervention. ObstetGynecol. 2006;108(2):469-77.

12. Sawyer A, Ayers S, Smith H. Pre and postnatal psychological wellbeing in Africa: a systematic review. J Affect Disord. 2010;123(1-3):17-29.

13. Kaaya SF, Mbwambo JK, Kilonzo GP, Van Den Borne $H$, Leshabari MT, Fawzi MC, et al. Socio-economic and partner relationship factors associated with antenatal depressive morbidity among pregnant women in Dar esSalaam,Tanzania. Tanzan J Health Res. 2010;12(1):23-35.

14. Woods SM, Melville JL, Guo Y, et al. Psychosocial stress during pregnancy. Am J ObstetGynecol. 2010;202(1):61.e1-7.

15. Pantha S, Hayes B, Yadav BK, Sharma P, Shrestha A, et al. Prevalence of Stress among Pregnant Women Attending Antenatal Care in a Tertiary Maternity Hospital in Kathmandu. J Women's Health Care. 2014;3(5):183.

16. Rwakerma M, Premji SS, Nyanza EC, Riziki P and Palacios-Derflingher L. Antenatal depression is associated with pregnancy-related anxiety, partner relations, and wealth in women in Northern Tanzania: a cross sectional study. BMC Women's Health. 2015 Sep;15:68. 